Pharmacology

\title{
Oral Drugs Related with Muscle Wasting and Sarcopenia. A Review
}

\author{
Lluis Campins ${ }^{a}$ Marcella Camps $^{a}$ Ariadna Riera $^{\mathrm{b}}$ Eulogio Pleguezuelos ${ }^{\mathrm{b}}$ \\ Juan Carlos Yebenes ${ }^{c}$ Mateu Serra-Prat ${ }^{d}$ \\ ${ }^{a}$ Department of Pharmacy, ${ }^{b}$ Department of Physical Medicine and Rehabilitation, ${ }^{c}$ Department of Critical Care, and \\ ${ }^{\mathrm{d}}$ Research Unit, Hospital de Mataró, Consorci Sanitari del Maresme, Mataró, Barcelona, Spain
}

\section{Key Words}

Sarcopenia $\cdot$ Muscle wasting $\cdot$ Angiotensin-converting

enzyme inhibitors · Statins · Antidiabetic drugs · Vitamin D

\begin{abstract}
Sarcopenia is a geriatric syndrome characterized by progressive and generalized loss of skeletal muscle mass and function. Reported prevalence of this geriatric syndrome, differs depending on the definition, the population and the method used to identify sarcopenia. The causes of sarcopenia are multifactorial, and can include genetic influence, immobility or disuse, endocrine factors, inflammation and nutritional deficiencies. These disorders involve an imbalance between anabolic and catabolic pathways that rules muscle mass. Many drugs taken regularly for common conditions may interact with some mechanisms that can alter the balance between protein synthesis and degradation. This may lead to a harmful or a beneficial effect on muscle mass and strength. Widely prescribed drugs could play an important role during the time of onset and development of sarcopenia. In this paper, we reviewed the current understanding of how can drugs contribute positively or negatively on sarcopenia and muscle wasting. We decided to focus this review on oral common drugs, which are usually prescribed in older adults, leaving aside other drugs as hormone therapy.
\end{abstract}

(c) 2016 S. Karger AG, Basel

\section{KARGER}

๑) 2016 S. Karger AG, Basel

E-Mail karger@karger.com

www.karger.com/pha

\section{Introduction}

The International Working Group on Sarcopenia defined sarcopenia as 'age-associated loss of skeletal muscle mass and function' [1]. This is similar to the European Working Group on Sarcopenia in Older People (EWGSOP), which provided a working definition of sarcopenia in 2010 as 'a syndrome characterized by progressive and generalized loss of skeletal muscle mass and strength with a risk of adverse outcomes such as physical disability, poor quality of life and death' [2]. The EWGSOP recommends using the presence of both low muscle mass and low muscle function (strength or performance) for the diagnosis of sarcopenia [2]. EWGSOP suggests a conceptual staging for this complex syndrome. Pre-sarcopenia is characterized by low muscle mass without impact on muscle strength or physical performance; sarcopenia is characterized by low muscle mass, plus low muscle strength or low physical performance; and severe sarcopenia is identified when all 3 criteria of the definition are met (low muscle mass, low muscle strength and low physical performance) [2]. According to this definition, while sarcopenia is mainly observed in older people, it can also develop in younger adults. For this reason, some authors have introduced the term dynapenia to describe the age-associated loss of muscle strength, which is not caused by neurologic or

Dr. Lluis Campins 
muscular diseases [3]. Prevalence of sarcopenia differs depending on the definition used, the population and the method used to identify sarcopenia. According to EWGSOP, the prevalence in $60-70$ years is reported as $5-13 \%$, while the prevalence ranges from 11 to $50 \%$ in people $>80$ years $[2,4]$.

\section{Pathophysiology and Muscle Wasting}

Sarcopenia is a geriatric syndrome with multiples causes, which can include genetic influence, immobility or disuse, endocrine factors, inflammation and nutritional deficiencies (fig. 1) [1,2]. These disorders involve an imbalance between anabolic and catabolic pathways that rules muscle mass. The major anabolic pathway involves activation of the Akt mammalian target of rapamycin (mTOR), which leads to increased muscle protein synthesis [5]. Insulin-like growth factor 1 (IGF-1), branchedchain aminoacids, exercise, testosterone and B2-adrenergics agents upregulate this pathway and are known to promote muscle growth [6]. During the aging process, there is a decline of anabolic hormones such as testosterone, growth hormone and IGF-1, leading to decreased protein synthesis [7]. Insulin resistance, which occurs with aging and obesity, plays an important role in decreasing available glucose and protein for muscle anabolism [7].

Muscle atrophy occurs when the rate of muscle protein degradation exceeds the rate of muscle protein synthesis. The major catabolic pathways include the activation of the ubiquitin proteasome pathway and calpain and caspases under transcriptional control of the transcription factors forkhead box $\mathrm{O}$ and nuclear factor (NF)- $\kappa \mathrm{B}$ [8]. Inflammation mediated by cytokines and inactivity are two of the most important situations which stimulates this transcription factors, especially NF- $\kappa B$ signaling [8]. Obesity and some diseases result in an increase in proinflammatory cytokines such as interleukin (IL)-6, IL-1 and/or tumor necrosis factor alpha, which lead to protein catabolism through the activation of NF$\kappa \mathrm{B}$ [9]. Aging is associated with an increase in some cytokines, but it is not clear if it is due to age alone or due to underlying comorbidities that accompany old age [10]. Another important pathway leading to muscle atrophy is the myostatin pathway, which acts by downregulating the Akt-mTOR pathway [6]. Other pathways, summarized by Ali and Garcia [8], that contribute to the onset of sarcopenia include an increase in muscle apoptosis and autophagy activity and a decrease in mitochondrial function and satellite cells, essentials for muscle repair.

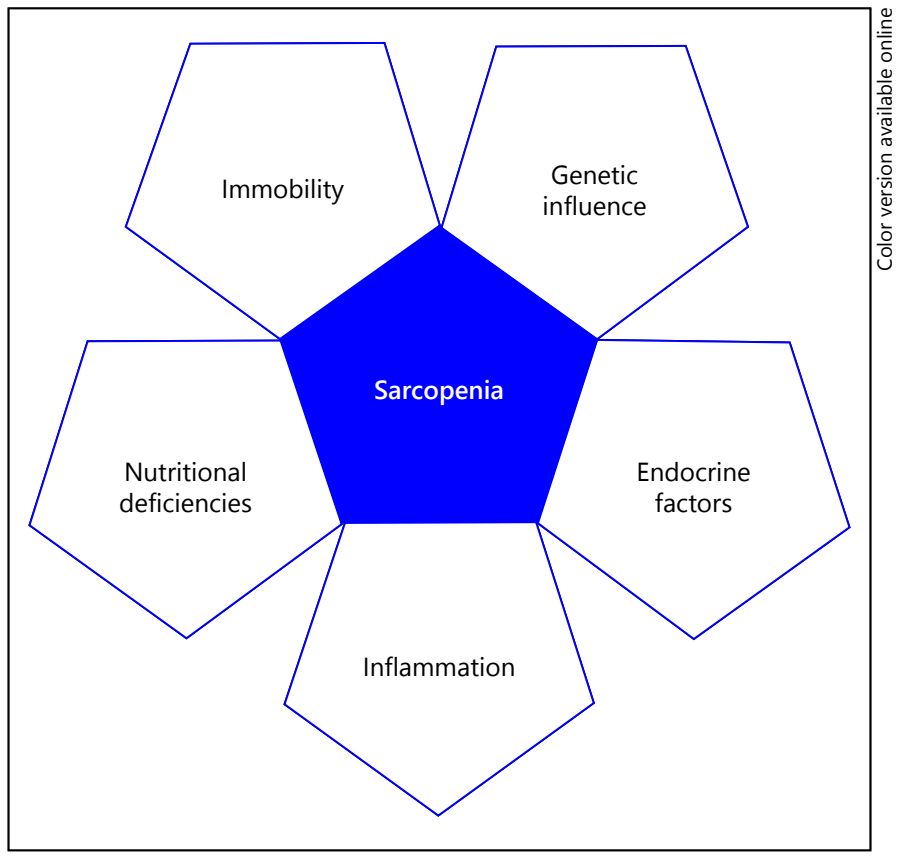

Fig. 1. Most important causes associated to sarcopenia.

In figure 2, we summarized the most important pathways and causes contributing to loss of muscle mass that can lead to sarcopenia.

\section{Objectives}

Many drugs taken regularly for common conditions may interact with some of these mechanisms. This may lead to a harmful or a beneficial effect on muscle mass and strength. In this paper, we reviewed the current understanding of how can drugs contribute positively or negatively on sarcopenia and muscle wasting (fig. 3). We decided to focus this review on oral common drugs, which are usually prescribed in older adults, leaving aside other drug as hormone therapy.

\section{Renin-Angiotensin System}

Renin converts angiotensinogen to angiotensin I, and this is converted to angiotensin II through the action of angiotensin-converting enzyme (ACE). ACE also catalyzes the inactivation of bradykinin. The formation of angiotensin II mainly results in a vasoconstriction, catecholamine release and aldosterone secretion, mediated by receptors AT1. It has been suggested that beneficial effects 


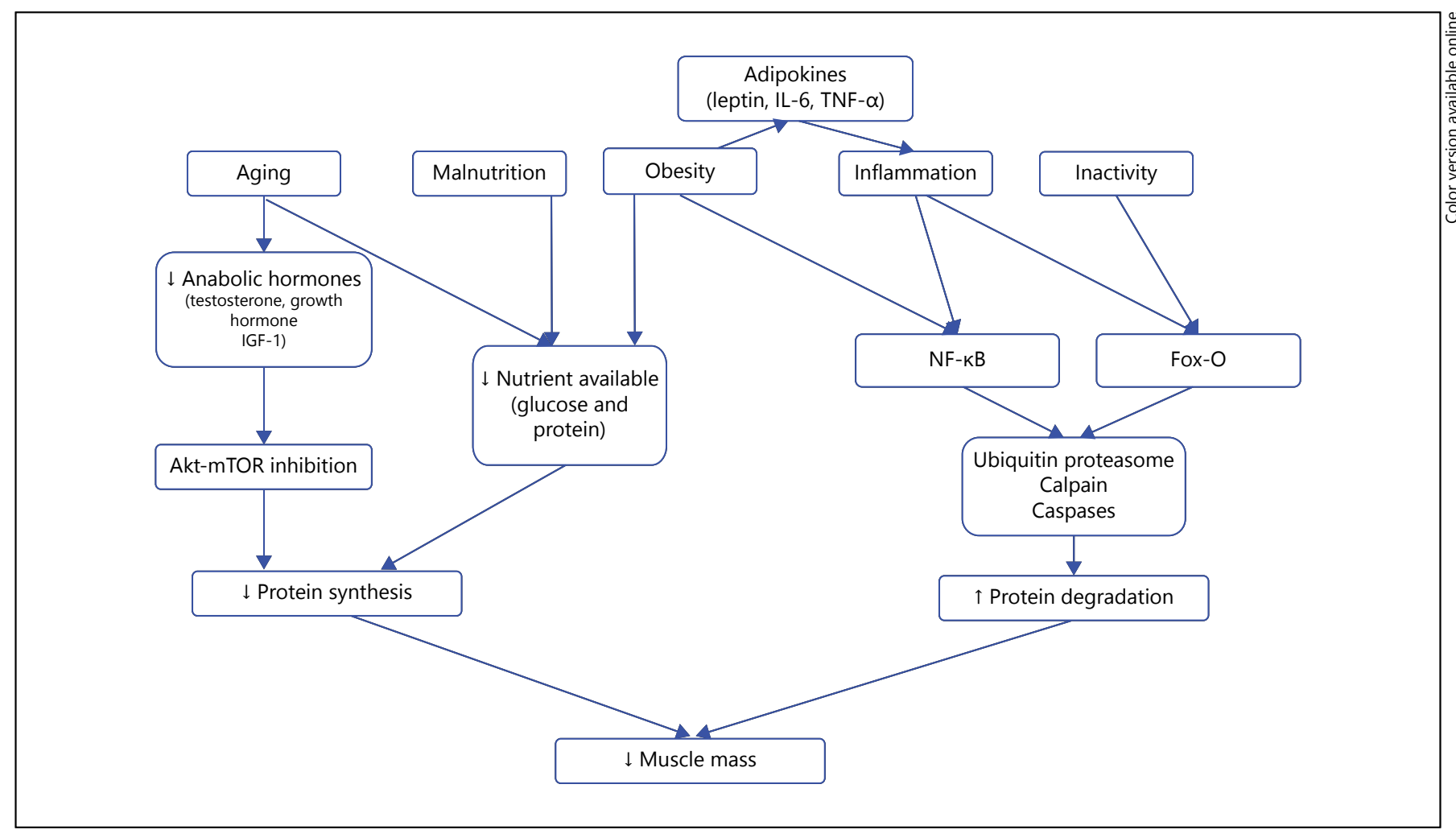

Fig. 2. Pathways associated to loss of muscle mass.

of ACE inhibitors and angiotensin receptors blockers (ARBs) is due to this improved oxygen delivery [11] and by direct positive actions on the skeletal muscle $[12,13]$.

\section{ACE Inhibitors}

Some studies have evaluated the impact of ACE inhibitors on muscle strength and performance. Onder et al. [14] showed a 3 years lower average decline in muscle strength and walking speed when ACE inhibitors were taken in an observational study among 641 aging disabled women. Other studies found similar results with better walking speed on persons taking ACE inhibitors $[15,16]$. In a double-blind randomized controlled trial, 130 older adults were assigned to receive either perindopril or placebo for 20 weeks. The mean 6-minute walking distance was significantly improved in the perindopril group relative to the placebo group [17]. Improving muscle strength and walking speed may have a protective effect on the risk of sarcopenia.

\section{Angiotensin Receptors Blockers}

ARBs block AT1 receptor thus leading to a decrease in angiotensin II levels. This mechanism assumes that the same beneficial effects are expected in skeletal muscle

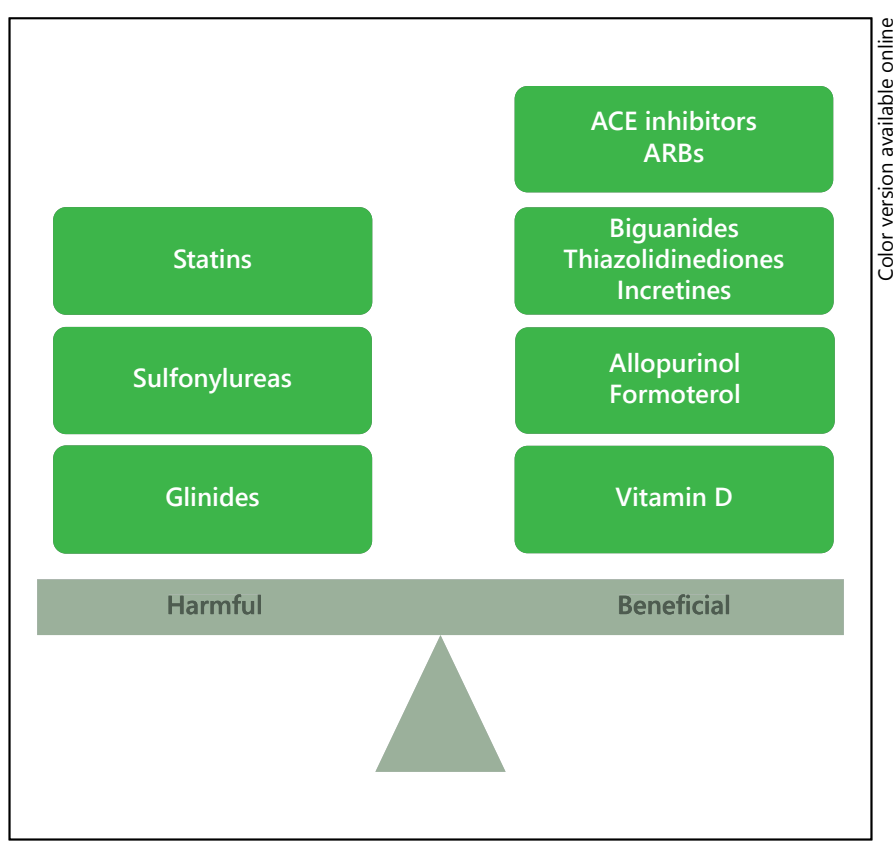

Fig. 3. Oral drugs associated to muscle function. 
than those seen with ACE inhibitors. Some authors showed an association between a decrease in the inflammatory cytokine IL- 6 and ARB therapy $[18,19]$. Burks et al. [20] indicate that the blockade of the AT1 receptor has beneficial effects on skeletal muscle remodeling in response to injury and conferring protection against disuse atrophy in sarcopenia by modulating the transforming growth factor- $\beta$ (a known inhibitor of skeletal muscle regenerator) and Akt-mTOR pathways. In a study with older mice, it is suggested that treatment with losartan improves measures of physical function, decreases the inflammatory cytokine IL- 6 and increases protective and antioxidant enzymes [21]. The Johns Hopkins University is conducting a clinical trial to see whether losartan can prevent the decrease in strength associated with aging, which will provide the evidence needed to clarify the association between sarcopenia and ARBs [22].

\section{Oral Antidiabetic Agents}

Diabetes mellitus is a syndrome with a prevalence that can reach $25 \%$ among those who are $>65$ years [23]. The association between diabetes and loss of muscle mass and strength is known [24-26] but is not entirely known how antidiabetic agents influence this association. It is nearly impossible to differentiate the effect of oral antidiabetic drugs from that of diabetes mellitus, but recently Cetrone et al. [27] published a review about how oral antidiabetics can affect muscular atrophy. The subfamilies most associated with muscle disorders are discussed in the following sections.

\section{Biguanides}

The mechanism of action of metformin is unknown, but it seems to acts by increasing insulin sensitivity. However, the effects of metformin on muscle are still uncertain and therefore a matter of debate. Perez et al. [28] showed a relationship between metformin treatment with reduced proinflammatory cytokines regardless of glucose. However, metformin causes the inhibition of mTOR complex through activation of the AMPactivated protein kinase, causing a decrease in anabolic effects mediated by mTOR [29]. According to a recent paper, metformin use does not alter the expression of mTOR arguing this theory [30]. There is currently a clinical trial examining the use of metformin in preventing the development of sarcopenia in older people with prediabetes, which will bring light to the current scenario [31].

\section{Thiazolidinediones}

This family of oral antidiabetic, called glitazone, is an PPAR receptor agonist with a high ability to increase insulin sensitivity and possibly their anabolic effects [32]. Studies in mice have shown a decrease in proteolysis and muscle atrophy with the use of rosiglitazone $[33,34]$.

\section{Potassium Channels Blockers}

Sulfonylureas are a broad family of drugs that act by blocking the potassium channels and by producing a secretagogue effect on insulin [35]. Some in vitro studies have shown an induction of cell apoptosis with therapeutic doses of sulfonylureas [36, 37], which can lead to atrophy $[38,39]$. Glinides have a mechanism of action similar to sulfonylureas with a shorter half-life [40], which also can cause atrophy in experimental animals [39]. However, the muscle effects of these drugs in humans are unknown.

\section{Incretins}

These oral agents inhibit the enzyme dipeptidil peptidase IV, which is responsible for degradation of endogenous incretin. They have hypertrophic and anti-apoptotic effects, as well as an improvement in insulin resistance sensitivity and muscle oxygen intake [41-44]. Despite being a relatively new drug, these beneficial actions on the muscle have made them very promising drugs against muscular atrophy and sarcopenia.

\section{Statins}

Statins are cholesterol lowering drugs widely used to reduce cardiovascular risk, even in the elderly. Although the drugs well tolerated, muscular side effects are fairly common [45] and may affect up to $29 \%$ of patients becoming the main reason for drug withdrawal [46]. This muscle toxicity is a syndrome that can arise from myalgia, muscle weakness and elevations of creatine kinase to rhabdomyolysis. It is dose dependent and usually resolves decreasing the dose or discontinuing treatment [47].

Traditionally, the mechanism of action of statins' muscle toxicity has been associated with decreased Coenzyme Q10, an essential component in the mitochondrial respiratory chain [48]. It seems however that this is not the only mechanism of toxicity, and some authors propose other ways which would also be involved in geranylgeranyl pyrophosphate, cell apoptosis and dysfunction in glucose oxidation $[49,50]$. Some studies have linked this muscular toxicity with muscle weakness $[51,52]$. In a 
3-year study monitoring 774 older adults, Scott et al. [53] associated greater decrease in muscle strength and increased risk of falls in patients who were treated with statins versus those who were non-treated.

\section{Vitamin D}

Vitamin $\mathrm{D}$ plays a role in numerous physiological processes and it is known that it has a much wider range of advantages than maintaining adequate serum calcium levels [54]. These properties can be dependent or independent of its binding on the nuclear receptor vitamin $\mathrm{D}$ receptor (VDR). Many studies have suggested that vitamin D is related to muscle strength and frailty [55-57].

Low vitamin $\mathrm{D}$ levels are common, especially in the elderly, where prevalence may reach $50 \%[58,59]$. This age-related reduction also appears to occur in VDR [60]. There is evidence to suggest that prolonged deficiency is associated with severe muscle weakness [61] and loss of muscle mass and strength [62]. In a 3-year follow-up study, lower levels of vitamin D were found to be predictive of decreased grip strength and muscle mass [63]. Some studies associate this weakness and loss of muscle mass with changes in muscle morphology, demonstrating a preferential atrophy of type II muscle fibers $[64,65]$. In old rats, 9 months of vitamin D depletion induced skeletal muscle atrophy [66].

In addition, it seems there is an increased risk of a decline in physical performance with low vitamin D levels $[67,68]$. In the InCHIANTI study, a prospective population-based study, 1,155 participants aged $\geq 65$ years were included and low vitamin D levels were associated with poor physical performance, measured by a battery of tests, including walking speed, the ability to stand from a chair and the ability to maintain balance in progressively more challenging positions [69]. Muscle strength and physical performance are linked to risk of falls, and there is a large evidence of low levels of vitamin $\mathrm{D}$ associated with risk of falls in the elderly [70-72]. Vitamin D supplementation in an aging population may be important for the preservation of physical function and the reduction in risk of falls [73]. In a clinical trial on burn patients, vitamin $\mathrm{D}$ and calcium supplementation increased quadriceps strength [74]. In the same sense, vitamin D supplementation significantly increased muscle strength [75], and a recent randomized controlled trial demonstrated that supplementation with vitamin $\mathrm{D}$ over 4 months in older women with low vitamin D levels resulted in a $10 \%$ increase in muscle fiber size [76]. A meta-analysis showed that whereas vitamin $\mathrm{D}$ supplementation increases proximal muscle strength of the lower extremities in adults with vitamin $\mathrm{D}$ deficiency, it does not have a significant effect on muscle strength in adults with baseline vitamin D levels $>25 \mathrm{nmol} / \mathrm{l}$ [77]. Same results have been shown in women after stroke, where vitamin D supplementation reverses muscular atrophy and increases strength [78].

Summarizing, vitamin D supplementation has demonstrated to have beneficial effects, increasing muscle strength and performance, and The Society on Sarcopenia, Cachexia and Wasting Diseases recommends checking vitamin $\mathrm{D}$ levels and replacing, if low, in all sarcopenic patients [79].

\section{Allopurinol}

Allopurinol is a drug widely used to treat gout. Its mechanism of action involves the reduction of plasma levels of uric acid from inhibiting xanthine oxidase (XO). Some authors have demonstrated a relationship between $\mathrm{XO}$ action and increased oxidative stress, declining muscle mass and strength in aged animals [80, 81]. Springer et al. $[82,83]$ showed that the inhibition of XO reduced levels of oxidative stress, maintaining muscle mass and reducing cachexia in cachectic animals. In another study with immobilized animals, Kondo et al. [84] showed an increase of 2 or 3 times the $\mathrm{XO}$ activity in the soleus muscle.

Therefore, it is reasonable to think that an inhibitor of $\mathrm{XO}$, such as allopurinol, may be able to prevent muscle atrophy or even sarcopenia. In this direction, treatment with allopurinol in rats with extremities suspended for 14 days prevented the atrophy of the soleus [85]. More recently in humans, Beveridge et al. [86], after analysis of 3,593 patients for 10 years in a rehabilitation unit and evaluating the Barthel Index at admission and discharge, demonstrated a greater improvement in allopurinoltreated patients compared to the untreated, suggesting an association between the drug and improved functionality.

\section{Formoterol}

This drug, a highly potent $\beta 2$-adrenoceptor-selective agonist which is used to treat bronchospasm associated with asthma, has been associated to an increased protein synthesis, decreased apoptosis and increased muscle regeneration $[87,88]$. This fact introduced the use of $\beta 2$ - 
adrenergic agonists as a possible drug for the treatment of cachexia [89]. In a study using rats affected by cancer cachexia, formoterol treatment reduces muscle wasting and does not negatively alter heart function [90]. any recommendation, there is growing evidence that shows that there is an association between drugs and muscle, and they may act as a trigger to develop sarcopenia and frailty. More research is needed to clarify most of the aspects mentioned in this review.

\section{Conclusion}

In this review, we described that some widely prescribed oral drugs may have an effect on muscle. Although these results are not sufficiently strong to support

\section{Disclosure Statement}

The authors of the present article declare that they have no conflicts of interest.

\section{References}

1 Fielding RA, Vellas B, Evans WJ, Bhasin S, Morley JE, Newman AB, Abellan van Kan G, Andrieu S, Bauer J, Breuille D, Cederholm T, Chandler J, de Meynard C, Donini L, Harris T, Kannt A, Keime Guibert F, Onder G, Papanicolaou D, Rolland Y, Rooks D, Sieber C, Souhami E, Verlaan S, Zamboni M: Sarcopenia: an undiagnosed condition in older adults. Current consensus definition: prevalence, etiology, and consequences. International working group on sarcopenia. J Am Med Dir Assoc 2011;12:249-256.

2 Cruz-Jentoft AJ, Baeyens JP, Bauer JM, Boirie Y, Cederholm T, Landi F, Martin FC, Michel JP, Rolland Y, Schneider SM, Topinková E, Vandewoude M, Zamboni M; European Working Group on Sarcopenia in Older People: Sarcopenia: European consensus on definition and diagnosis: report of the European working group on sarcopenia in older people. Age Ageing 2010;39:412-423.

3 Clark BC, Manini TM: Sarcopenia =/= dynapenia. J Gerontol A Biol Sci Med Sci 2008;63: 829-834.

4 Cruz-Jentoft AJ, Landi F, Schneider SM, Zúñiga C, Arai H, Boirie Y, Chen LK, Fielding RA, Martin FC, Michel JP, Sieber C, Stout JR, Studenski SA, Vellas B, Woo J, Zamboni M, Cederholm T: Prevalence of and interventions for sarcopenia in ageing adults: a systematic review. Report of the international sarcopenia initiative (EWGSOP and IWGS). Age Ageing 2014;43:748-759.

5 Bodine SC, Stitt TN, Gonzalez M, Kline WO, Stover GL, Bauerlein R, Zlotchenko E, Scrimgeour A, Lawrence JC, Glass DJ, Yancopoulos GD: Akt/mTOR pathway is a crucial regulator of skeletal muscle hypertrophy and can prevent muscle atrophy in vivo. Nat Cell Biol 2001;3:1014-1019.

6 Schiaffino S, Dyar KA, Ciciliot S, Blaauw B, Sandri M: Mechanisms regulating skeletal muscle growth and atrophy. FEBS J 2013;280: 4294-4314.

7 Morley JE, Anker SD, von Haehling S: Prevalence, incidence, and clinical impact of sarcopenia: facts, numbers, and epidemiology-up- date 2014. J Cachexia Sarcopenia Muscle 2014;5:253-259.

8 Ali S, Garcia JM: Sarcopenia, cachexia and aging: diagnosis, mechanisms and therapeutic options - a mini-review. Gerontology 2014; 60:294-305.

9 von Haehling S, Steinbeck L, Doehner W, Springer J, Anker SD: Musclewasting in heart failure: an overview. Int J BiochemCell Biol 2013;45:2257-2265.

10 Cohen HJ, Pieper CF, Harris T, Rao KM, Currie MS: The association of plasma IL-6 levels with functional disability in communitydwelling elderly. J Gerontol A Biol Sci Med Sci 1997;52:M201-M208.

11 Rolland Y, Onder G, Morley JE, Gillette-Guyonet S, Abellan van Kan G, Vellas B: Current and future pharmacologic treatment of sarcopenia. Clin Geriatr Med 2011;27:423-447.

12 Onder G, Vedova CD, Pahor M: Effects of ACE inhibitors on skeletal muscle. Curr Pharm Des 2006;12:2057-2064.

13 Sumukadas D, Struthers AD, McMurdo ME: Sarcopenia - a potential target for angiotensin-converting enzyme inhibition? Gerontology 2006;52:237-242.

14 Onder G, Penninx BW, Balkrishnan R, Fried LP, Chaves PH, Williamson J, Carter C, Di Bari M, Guralnik JM, Pahor M: Relation between use of angiotensinconverting enzyme inhibitors and muscle strength and physical function in older women: an observational study. Lancet 2002;359:926-930.

15 Sumukadas D, Witham MD, Struthers AD, et al: ACE inhibitors as a therapy for sarcopenia - evidence and possible mechanisms. J Nutr Health Aging 2008;12:480-485.

16 Witham MD, Sumukadas D, McMurdo ME: ACE inhibitors for sarcopenia - as good as exercise training? Age Ageing 2008;37:363-365.

17 Sumukadas D, Witham MD, Struthers AD, et al: Effect of perindopril on physical function in elderly people with functional impairment: a randomized controlled trial. CMAJ 2007; 177:867-874

18 Ogawa S, Mori T, Nako K, et al: Angiotensin II type 1 receptor blockers reduce urinary ox- idative stress markers in hypertensive diabetic nephropathy. Hypertension 2006;47:699705

19 Takagi H, Mizuno Y, Yamamoto H, Goto SN Umemoto T; All-Literature Investigation of Cardiovascular Evidence Group: Effects of telmisartan therapy on interleukin- 6 and tumor necrosis factor-alpha levels: a meta-analysis of randomized controlled trials. Hypertens Res 2013;36:368-373.

20 Burks TN, Andres-Mateos E, Marx R, Mejias R, Van Erp C, Simmers JL, Walston JD, Ward CW, Cohn RD: Losartan restores skeletal muscle remodeling and protects against disuse atrophy in sarcopenia. Sci Transl Med 2011;3:82ra37.

21 Lin $\mathrm{CH}$, Yang H, Xue QL, Chuang YF, Roy CN, Abadir P, Walston JD: Losartan improves measures of activity, inflammation, and oxidative stress in older mice. Exp Gerontol 2014;58:174-178.

22 ClinicalTrials.gov: A Study of Muscle Strength Maintenance in Older Adults. Bethesda, National Library of Medicine (US), 2013. https:// clinicaltrials.gov/ct2/show/NCT01989793 (cited June 21, 2015).

23 Centers for Disease Control and Prevention: National Diabetes Fact Sheet: General Information and National Estimates on Diabetes in the United States, 2011. Atlanta, Department of Health and Human Services, Centers for Disease Control and Prevention, 2011.

24 Sinclair A, Morley JE, Rodriguez-Mañas L, Paolisso G, Bayer T, Zeyfang A, et al: Diabetes mellitus in older people: position statement on behalf of the international association of gerontology and geriatrics (IAGG), the European diabetes working party for older people (EDWPOP), and the international task force of experts in diabetes. J Am Med Dir Assoc 2012;13:497-502.

25 Leenders M, Verdijk LB, van der Hoeven L, Adam JJ, van Kranenburg J, Nilwik R, et al: Patients with type 2 diabetes show a greater decline in muscle mass, muscle strength, and functional capacity with aging. J Am Med Dir Assoc 2013;14:585-592. 
26 Kim KS, Park KS, Kim MJ, Kim SK, Cho YW, Park SW: Type 2 diabetes is associated with low muscle mass in older adults. Geriatr Gerontol Int 2014;14(suppl 1):115-121.

27 Cetrone M, Mele A, Tricarico D: Effects of the antidiabetic drugs on the age-related atrophy and sarcopenia associated with diabetes type II. Curr Diabetes Rev 2014;10:231-237.

28 Perez A, Jacks R, Arora V, et al: Effects of pioglitazone and metformin fixed-dose combination therapy on cardiovascular risk markers of inflammation and lipid profile compared with pioglitazone and metformin monotherapy in patients with type 2 diabetes. J Clin Hypertens (Greenwich) 2010;12:973982.

29 Musi N, Hirshman MF, Nygren J, Svanfeldt M, Bavenholm P, Rooyackers O, Zhou G, Williamson JM, Ljunqvist $O$, Efendic $S$, Moller DE, Thorell A, Goodyear LJ: Metformin increases AMP-activated protein kinase activity in skeletal muscle of subjects with type 2 diabetes. Diabetes 2002;51:20742081.

30 Dungan CM, Li Z, Wright DC, Williamson DL: Hyperactive mTORC1 signaling is unaffected by metformin treatment in aged skeletal muscle. Muscle Nerve 2016;53:107-117.

31 ClinicalTrials.gov: Metformin and Muscle in Insulin-Resistant Older Veterans. Bethesda, National Library of Medicine (US), 2013. https://clinicaltrials.gov/ct2/show/ NCT01804049 (cited June 21, 2015).

32 Miyazaki Y, Mahankali A, Matsuda M, et al: Effect of pioglitazone on abdominal fat distribution and insulin sensitivity in type 2 diabetic patients. J Clin Endocrinol Metab 2002; 87:2784-2791.

33 Wang X, Hu Z, Hu J, Du J, Mitch WE: Insulin resistance accelerates muscle protein degradation: activation of the ubiquitinproteasome pathway by defects in muscle cell signaling. Endocrinology 2006;147:4160-4168.

34 Asp ML, Tian M, Wendel AA, Belury MA: Evidence for the contribution of insulin resistance to the development of cachexia in tumor-bearing mice. Int J Cancer 2010;126: 756-763.

35 Tricarico D, Camerino DC: ATP-sensitive K+ channels of skeletal muscle fibers from young adult and aged rats: possible involvement of thiol-dependent redox mechanisms in the age-related modifications of their biophysical and pharmacological properties. Mol Pharmacol 1994;46:754-761.

36 Maedler K, Carr RD, Bosco D, Zuellig RA, Berney T, Donath MY: Sulfonylurea induced beta-cell apoptosis in cultured human islets. J Clin Endocrinol Metab 2005;90:501-506.

37 Wajchenberg BL: Beta-cell failure in diabetes and preservation by clinical treatment. Endocr Rev 2007;28:187-218.

38 Mele A, Buttiglione M, Cannone G, Vitiello F, Camerino DC, Tricarico D: Opening/blocking actions of pyruvate kinase antibodies on neuronal and muscular KATP channels. Pharmacol Res 2012;66:401-408.
39 Mele A, Calzolaro S, Cannone G, Cetrone M, Conte D, Tricarico D: Database search of spontaneous reports and pharmacological investigations on the sulfonylureas and glinidesinduced atrophy in skeletal muscle. Pharmacol Res Perspect 2014;2:e0028.

40 Malaisse WJ: Pharmacology of the meglitinide analogs: new treatment options for type 2 diabetes mellitus. Treat Endocrinol 2003;2: 401-414.

41 Doyle ME, Egan JM: Mechanisms of action of glucagon-like peptide 1 in the pancreas. Pharmacol Ther 2007;113:546-593.

42 Buteau J: GLP-1 receptor signaling: effects on pancreatic beta-cell proliferation and survival. Diabetes Metab 2008;34(suppl 2):73-77.

43 Nyström T: The potential beneficial role of glucagon-like peptide- 1 in endothelial dysfunction and heart failure associated with insulin resistance. Horm Metab Res 2008;40: 593-606.

44 Chai W, Dong Z, Wang N, Wang W, Tao L, Cao W, Liu Z: Glucagon-like peptide 1 recruits microvasculature and increases glucose use in muscle via a nitric oxide-dependent mechanism. Diabetes 2012;61:888-896.

45 Bruckert E, Hayem G, Dejager S, Yau C, Begaud B: Mild to moderate muscular symptoms with high-dosage statin therapy in hyperlipidemic patient - the PRIMO study. Cardiovasc Drugs Ther 2005; 19:403-414.

46 Wei M, Ito MK, Cohen JD, Brinton EA, Jacobson TA: Predictors of statin adherence, switching, and discontinuation in the USAGE survey: understanding the use of statins in America and gaps in patient education. J Clin Lipidol 2013;7:472-483.

47 Jones JD, Kirsch HL, Wortmann RL, Pillinger $\mathrm{MH}$ : The causes of drug-induced muscle toxicity. Curr Opin Rheumatol 2014;26:697-703.

48 Marcoff L, Thompson PD: The role of coenzyme Q10 in statin-associated myopathy: a systematic review. J Am Coll Cardiol 2007;49: 2231-2237.

49 Itagaki M, Takaguri A, Kano S, et al: Possible mechanisms underlying statin-induced skeletal muscle toxicity in L6 fibroblasts and in rats. J Pharmacol Sci 2009;109:94-101.

50 Smith R, Solberg R, Jacobsen LL, et al: Simvastatin inhibits glucose metabolism and legumain activity in human myotubes. PLoS One 2014;9:e85721.

51 Phillips PS, Haas RH, Bannykh S, et al: Statinassociated myopathy with normal creatine kinase levels. Ann Intern Med 2002;137:581585.

52 Thompson PD, Zmuda JM, Domalik LJ, Zimet RJ, Staggers J, Guyton JR: Lovastatin increases exercise-induced skeletal muscle injury. Metabolism 1997;46:1206-1210.

53 Scott D, Blizzard L, Fell J, Jones G: Statin therapy, muscle function and falls risk in community-dwelling older adults. QJM 2009;102: 625-633.

54 Cavalier E, Delanaye P, Chapelle JP, Souberbielle JC: Vitamin D: current status and perspectives. Clin Chem Lab Med 2009;47:120-127.
55 Ensrud KE, Blackwell TL, Cauley JA, et al; Osteoporotic Fractures in Men Study Group: Circulating 25-hydroxyvitamin D levels and frailty in older men: the osteoporotic fractures in men study. J Am Geriatr Soc 2011;59:101106.

56 Morley JE: Should all long-term care residents receive vitamin D? J Am Med Dir Assoc 2007; 8:69-70.

57 Tajar A, Lee DM, Pye SR, et al: The association of frailty with serum 25-hydroxyvitamin $\mathrm{D}$ and parathyroid hormone levels in older European men. Age Ageing 2012;42:352-359.

58 Braddy KK, Imam SN, Palla KR, et al: Vitamin $\mathrm{D}$ deficiency/insufficiency practice patterns in a veterans health administration long-term care population: a retrospective analysis. J Am Med Dir Assoc 2009;10:653-657.

59 Islam T, Peiris P, Copeland RJ, et al: Vitamin D: lessons from the veterans population. J Am Med Dir Assoc 2011;12:257-262.

60 Montero-Odasso M, Duque G: Vitamin D in the aging musculoskeletal system: an authentic strength preserving hormone. Mol Aspects Med 2005;26:203-219.

61 Holick MF: Vitamin D deficiency. N Engl J Med 2007;357:266-281.

62 Bischoff-Ferrari HA, Dietrich T, Orav EJ, et al: Higher 25-hydroxyvitamin D concentrations are associated with better lower-extremity function in both active and inactive persons aged $>$ or $=60 \mathrm{y}$. Am J Clin Nutr 2004;80: $752-758$.

63 Visser M, Deeg DJ, Lips P: Low vitamin D and high parathyroid hormone levels as determinants of loss of muscle strength and muscle mass (sarcopenia): the longitudinal aging study Amsterdam. J Clin Endocrinol Metab 2003;88:5766-5772.

64 Yoshikawa S, Nakamura T, Tanabe H, Imamura T: Osteomalacic myopathy. Endocrinol Jpn 1979;26(suppl):65-72.

65 Palmucci L, Bertolotto A, Doriguzzi C, Mongini T, Coda R: Osteomalacic myopathy in a case of diffuse nodular lipomatosis of the small bowel. Acta Neurol Belg 1982;82:65-71.

66 Domingues-Faria C, Chanet A, Salles J, Berry A, Giraudet C, Patrac V, Denis P, Bouton K, Goncalves-Mendes N, Vasson MP, Boirie Y, Walrand S: Vitamin D deficiency down-regulates Notch pathway contributing to skeletal muscle atrophy in old Wistar rats. Nutr Metab (Lond) 2014; 11:47.

67 Wicherts IS, van Schoor NM, Boeke AJ, et al: Vitamin D status predicts physical performance and its decline in older persons. J Clin Endocrinol Metab 2007;92:2058-2065.

68 Houston DK, Tooze JA, Neiberg RH, et al: 25-Hydroxyvitamin D status and change in physical performance and strength in older adults: the health, aging, and body composition study. Am J Epidemiol 2012;176:10251034.

69 Houston DK, Cesari M, Ferrucci L, et al: Association between vitamin $\mathrm{D}$ status and physical performance: the InCHIANTI study. J Gerontol A Biol Sci Med Sci 2007;62:440-446. 
70 Flicker L, Mead K, MacInnis RJ, et al: Serum vitamin $\mathrm{D}$ and falls in older women in residential care in Australia. J Am Geriatr Soc 2003;51:1533-1538.

71 Faulkner KA, Cauley JA, Zmuda JM, et al: Higher 1,25-dihydroxyvitamin D3 concentrations associated with lower fall rates in older community-dwelling women. Osteoporos Int 2006; 17:1318-1328.

72 Snijder MB, van Schoor NM, Pluijm SM, et al: Vitamin D status in relation to one-year risk of recurrent falling in older men and women. J Clin Endocrinol Metab 2006;91: 2980-2985.

73 Rizzoli R, Stevenson JC, Bauer JM, van Loon LJ, Walrand S, Kanis JA, Cooper C, Brandi ML, Diez-Perez A, Reginster JY; ESCEO Task Force: The role of dietary protein and vitamin $\mathrm{D}$ in maintaining musculoskeletal health in postmenopausal women: a consensus statement from the European society for clinical and economic aspects of osteoporosis and osteoarthritis (ESCEO). Maturitas 2014;79: 122-132.

74 Rousseau AF, Foidart-Desalle M, Ledoux D, Remy C, Croisier JL, Damas P, Cavalier E: Effects of cholecalciferol supplementation and optimized calcium intakes on vitamin D status, muscle strength and bone health: a oneyear pilot randomized controlled trial in adults with severe burns. Burns 2015;41:317325.

75 Muir SW, Montero-Odasso M: Effect of vitamin D supplementation on musclestrength, gait and balance in older adults: a systematic review and meta-analysis. J Am Geriatr Soc 2011;59:2291-2300.

76 Ceglia L, Niramitmahapanya S, da Silva Morais M, Rivas DA, Harris SS, Bischoff-Ferrari
$\mathrm{H}$, et al: A randomized study on the effect of vitamin D3 supplementation on skeletal muscle morphology and vitamin $\mathrm{D}$ receptor concentration in older women. J Clin Endocrinol Metab 2013;98:E1927-E1935.

77 Stockton KA, Mengersen K, Paratz JD, et al. Effect of vitamin D supplementation on muscle strength: a systematic review and metaanalysis. Osteoporos Int 2011;22:859-871.

78 Sato Y, Iwamoto J, Kanoko T, Satoh K: Lowdose vitamin D prevents muscular atrophy and reduces falls and hip fractures in women after stroke: a randomized controlled trial. Cerebrovasc Dis 2005;20:187-192.

79 Morley JE, Argiles JM, Evans WJ, Bhasin S, Cella D, Deutz NE, Doehner W, Fearon KC, Ferrucci L, Hellerstein MK, Kalantar-Zadeh K, Lochs H, MacDonald N, Mulligan K, Muscaritoli M, Ponikowski P, Posthauer ME, Rossi Fanelli F, Schambelan M, Schols AM, Schuster MW, Anker SD; Society for Sarcopenia, Cachexia, and Wasting Disease: Nutritional recommendations for the management of sarcopenia. J Am Med Dir Assoc 2010;11: 391-396.

80 Aranda R, Domenech E, Rus AD, Real JT, Sastre J, Vina J, et al: Age-related increase xanthine oxidase activity in human plasma and rat tissues. Free Radic Res 2007;41:11951200.

81 Lambertucci RH, Levada-Pires AC, Rossoni LV, Curi R, Pithon-Curi TC: Effects of aerobic exercise training on antioxidant enzyme activities and mRNA levels in soleus muscle from young and aged rats. Mech Ageing Dev 2007; 128:267-275.

82 Springer J, Tschirner A, Hartman K, Palus S, Wirth EK, Ruis SB, et al: Inhibition of xanthine oxidase reduces wasting and improves outcome in a rat model of cancer cachexia. Int J Cancer 2012;131:2187-2196.

83 Springer J, Tschirner A, Hartman K, von Haehling S, Anker SD, Doehner W: The xanthine oxidase inhibitor oxypurinol reduces cancer cachexia-inducedcardiomyopathy. Int J Cardiol 2013;168:3527-3531.

84 Kondo H, Nakagaki I, Sasaki S, Hori S, Itokawa Y: Mechanism of oxidative stress in skeletal muscle atrophied by immobilization. Am J Physiol 1993;265(6 pt 1):E839-E844.

85 Derbre F, Ferrando B, Gomez-Cabrera MC, Sanchis-Gomar F, Martinez-Bello VE, OlasoGonzalez G, et al: Inhibition of xanthine oxidase by allopurinol preventsskeletal muscle atrophy: role of p38 MAPKinase and E3 ubiquitin ligases. PLoS One 2012;7:e46668.

86 Beveridge LA, Ramage L, McMurdo ME, George J, Witham MD: Allopurinol use is associated with greater functional gains in older rehabilitation patients. Age Ageing 2013;42: 400-404.

87 Busquets S, Figueras MT, Fuster G, Almendro V, Moore-Carrasco R, Ametller E, et al: Anticachectic effects of formoterol: a drug for potential treatment of muscle wasting. Cancer Res 2004;64:6725-6731.

88 Ametller E, Busquets S, Fuster G, et al: Formoterol may activate rat muscle regeneration during cancer cachexia. Insciences J 2011;1: $1-17$.

89 Argilés JM, López-Soriano FJ, Busquets S: Novel approaches to the treatment of cachexia. Drug Discov Today 2008;13:73-78.

90 Toledo M, Springer J, Busquets S, Tschirner A, López-Soriano FJ, Anker SD, Argilés JM: Formoterol in the treatment of experimental cancer cachexia: effects on heart function. J Cachexia Sarcopenia Muscle 2014;5:315-320. 